Dinamika Sosial Budaya, Vol 20, No. 1, Juni 2018, pp 66-71

p-ISSN: 1410-9859\& e-ISSN: 2580-8524

http://journals.usm.ac.id/index.php/jdsb

\title{
EFEKTIVITAS NONTON BARENG DAN SHARING DALAM KEGIATAN PARENTING DI LEMBAGA PAUD
}

\author{
Sri Kurnianingsih \\ Program Studi Psikologi, Fakultas Psikologi, Universitas Semarang \\ skurnianingsih2003@yahoo.com \\ Agung Santoso Pribadi \\ Program Studi Psikologi, Fakultas Psikologi, Universitas Semarang \\ agung84@usm.ac.id
}

\begin{abstract}
Participants of this research were 31 parents (between 21 - 56yo, from primary school to undergraduate) in Pos PAUD Menur. They were attending nine times weekly parenting class. Every meeting, they watched short movie about family related to the theme. Those were three big themes: reflective relationship (4 meetings), positive disiplin (3 meetings), and effective study (2 meetings). Critical points of the movie were also delivered as part of the movie. After watching each movie, participants shared their personal experiences related to the topic. Data were taken three times (based on big themes) through questionnaires. The result shown that the understanding of parents regarding topics that were delivered were increased.
\end{abstract}

key words: parenting, watching movie together, sharing, PAUD

\begin{abstract}
Abstrak
Tujuan penelitian ini adalah untuk menguji kelas parenting terhadap perubahan kognitif afektif dan psikomotor orangtua Penelitian ini dilakukan pada 31 orangtua di PosPAUD Menur yang mengikuti sembilan kali pertemuan parenting tiap hari Senin. Subjek berusia 21 - 56 tahun dengan pendidikan antara SD hingga S1. Dalam tiap pertemuan diputarkan film pendek komedi keluarga sesuai dengan tema. Terdapat tiga besara tema yaitu hubungan reflektif (4 pertemuan), disipilin positif ( 3 pertemuan), dan belajar efektif ( 2 pertemuan). Dalam film itu juga disampaikan secara singkat poin penting dari film yang ditonton. Selanjutnya orangtua diajak untuk sharing mengenai topik tersebut dikaitkan dengan pengalaman pribadi. Kuesioner pre dan post diberikan sebanyak tiga kali sesuai dengan tema besar. Hasil penelitian menunjukkan adanya peningkatan pemahaman orangtua mengenai materi yang diberikan dengan model nonton bareng dan sharing tersebut.
\end{abstract}

kata kunci: parenting, nonton bareng, sharing, PAUD 
Dinamika Sosial Budaya, Vol 20, No. 1, Juni 2018, pp 66-71

p-ISSN: 1410-9859\& e-ISSN: 2580-8524

http://journals.usm.ac.id/index.php/jdsb

\section{PENDAHULUAN}

Anak merupakan harta yang sangat berharga bagi sebuah bangsa. Anak akan menjadi generasi penerus yang suatu saat nanti akan menentukan perkembangan suatu negara. Anak sebagai generasi penerus tidak dapat dipisahkan dari lingkungan sosialnya. Keluarga adalah lingkungan sosial pertama dan kemudian teman sebaya, sekolah, lingkungan tempat tinggal, dan masyarakat yang lebih luas, merupakan tempat dimana anak akan mengembangkan dirinya.

Keluarga sebagai tempat pertama anak melakukan hubungan sosial menyebabkan keluarga sebagai agen sosial. Jika anak mengalami masalah dalam perkembangan sosialnya maka keluargalah yang ditunjuk sebagai yang bertanggung jawab atas masalah anak tersebut. Hal ini menjadikan peran orangtua sebagai pusat pengasuhan dalam keluarga sangatlah penting.

Sesuai dengan pendapat Hurlock (2011) bahwa orang yang paling penting bagi anak adalah orangtua, guru, dan teman sebaya (peer group). Melalui orangtua, guru dan teman sebaya anak mengenal sesuatu positif dan negatif. Anak mulai belajar dan meniru apa yang dilihatnya, terutama adalah perilaku orangtua, sebab keluarga merupakan salah satu pembentuk karakter anak. Pengasuhan keluarga sangat penting bagi perkembangan anak. Dengan demikian anak harus diasuh dengan hal-hal yang baik, yaitu mulai dengan mengenalkan agama, mengajarkan disiplin, berperilaku jujur, suka menolong, dan hal-hal yang positif harus diajarkan orangtua kepada anak sedini mungkin. Hal tersebut dilakukan agar tertanam atau terinternalisasi dalam jiwa anak (Hurlock, 2011). Kesalahan dalam pengasuhan anak juga dapat membawa dampak ketika dewasa nanti. Seorang anak akan merasa

trauma bila pengasuhan di keluarganya dilakukan dengan cara memaksa (koersif). Lain halnya jika anak selalu dipenuhi permintaannya oleh orangtua. Pola demikian akan membuat mereka menjadi pribadi yang manja. Oleh karena itu, orangtua harus bisa menerapkan pola pengasuhan yang fleksibel namun tetap bisa menanamkan nilai positif kepada anak

Dalam pengasuhan terdapat $5 \mathrm{C}$ atau $5 \mathrm{~K}$ yang perlu dimiliki orangtua atau pendidik (Istavin Asia Pacific, dalam Sumarno, 2014), yaitu: communication (komunikasi), collaboration (kolaborasi), control (kontrol), creativity (kreativitas) , dan consistency (konsistensi). Pertama adalah komunikasi. Orangtua dan pendidik harus mengetahui bahwa komunikasi yang konsisten, dengan sikap yang benar dan harapan yang benar, adalah keterampilan yang paling penting dalam mengubah anak. Ini adalah tindakan kunci orangtua yang harus dipelajari untuk mencoba berkomunikasi dengan anaknya. Kedua kolaborasi. Banyak orangtua menghindar dari bekerjasama dengan guru anak-anaknya, apakah akibat berbeda persepsi, prasangka, ketakutan atau rasa enggan. Terkadang, hal ini terjadi karena situasi ekonomi yang membutuhkan orangtua untuk fokus pada pemenuhan kebutuhan keluarga, sehingga menyerahkan pengajaran anak mereka pada pendidik di lembaga. Ketiga. Kontrol. Kontrol adalah disiplin yang bukan identik dengan hukuman. Sebagai pendidik tugasnya adalah mengingatkan orangtua tujuan kontrol anak yang sebenarnya. Saat anak berperilaku buruk, mereka sedang belajar mengetahui mana perilaku yang pantas dan sampai dimana batasan yang diberikan oleh orang dewasa. Keempat adalah kreativitas. Pengasuhan efektif perlu kreativitas, karena tiap anak berbeda satu dari yang lain. Ada banyak cara dalam menghadapi masalah pengasuhan dari satu anak ke anak yang lain. Banyak 
Dinamika Sosial Budaya, Vol 20, No. 1, Juni 2018, pp 66-71

p-ISSN: 1410-9859\& e-ISSN: 2580-8524

http://journals.usm.ac.id/index.php/jdsb

orangtua percaya bahwa, akan lebih baik menggunakan metode pengasuhan yang sama seperti orangtua mereka, orangtua lain percaya bahwa metode yang digunakan pada anak yang lebih tua akan berhasil pada anak yang lebih muda. Hal tersebut bukanlah realitas pengasuhan saat ini. Terakhir konsistensi. Seiring perkembangan pikiran anak, otak akan memproses pesan secara alami, namun agar pesan-pesan tersebut dapat diterima dan diterapkan maka diperlukan konsistensi. Jika orangtua tetap konsisten dengan pesan dan metode pengasuhan yang digunakan, anak-anak akan mulai menerima disiplin, sehingga komunikasi positif antara anak dan orangtua dapat berkembang.

Keterampilan pengasuhan menjadi masalah yang mengemuka pada saat ini. Kesibukan, pengaruh teknologi dalam komunikasi, tuntutan ekonomi, dan perubahan sosial lain mempengaruhi pola pengasuhan yang terjadi dalam keluarga. Akibatnya anak menjadi korban atas ketidakmampuan orangtua dalam memberikan pengasuhan yang tepat pada anak.

Kementerian Pendidikan dan Kebudayaan menengarai kondisi ini dan membentuk Direktorat Pembinaan dan Pendidikan Keluarga yang fokus pada program-program pengasuhan anak dalam keluarga. Salah satu program yang diterapkan adalah program parenting di lembaga sekolah dari PAUD hingga SMA. Dalam program tersebut orangtua diharapkan terlibat aktif dalam pendidikan anak di sekolah dan diberikan edukasi mengenai pengasuhan melalui beragam media. Beberapa contoh kegiatan yang diprogramkan yaitu pertemuan rutin, pelatihan, terlibat aktif di kelas anak, dan berbagai kegiatan edukasi lain.

PAUD menjadi salah satu jenjang pendidikan yang memperoleh intervensi penguatan orangtua dalam pengasuhan. Usia emas anak usia dini ( $0-6$ tahun) memperoleh perhatian yang besar dari semua 
Dinamika Sosial Budaya, Vol 20, No. 1, Juni 2018, pp 66-71

p-ISSN: 1410-9859\& e-ISSN: 2580-8524

http://journals.usm.ac.id/index.php/jdsb

tingkatan perkembangan dunia lainnya seperti dunia

orang dewasa, bahasa, adat istiadat dan kebudayaan.

Keluarga merupakan pendidikan yang pertama yang membangun kreativitas anak itu sendiri, Jika sejak kecil anak kurang mendapat pendidikan dari keluarga, maka akan menimbulkan berbagai dampak negatif bagi anak seperti kesulitan beradaptasi dengan lingkungan sosial, mengalami kesulitan untuk menerima pelajaran karena kurang mendapat perhatian orangtua. Karena itulah orangtua dituntut untuk memberikan pendidikan sedini mungkin bagi anak. Tujuannya agar saat anak sudah mulai beradaptasi dengan dunia luar, anak tidak akan mudah terbawa kedalam hal-hal negatif yang banyak terjadi di lingkungan sosial. Meskipun demikian, masih banyak juga keluarga yang tidak terlalu memikirkan pendidikan bagi anak-anaknya. Tidak sedikit orangtua yang melalaikan tanggung jawab mereka untuk memberikan pendidikan dan pengetahuan sedini mungkin kepada anak karena berbagai faktor.

Salah satu strategi untuk meningkatkan pengetahuan dan ketrampilan orangtua adalah mengadakan kegiatan parenting di lembaga sekolah. Diharapkan terjadi perubahan pemahaman orangtua mengenai pola pengasuhan yang akan mempengaruhi aspek kognitif, afektif, dan psikomotor (perilaku) mereka. Dampak selanjutnya dari perubahan, diharapkan orangtua akan memiliki kemampuan untuk memberikan pengasuhan yang tepat pada anaknya sehingga potensi anak dapat muncul dengan maksimal. Adapun tujuan penelitian ini adalah untuk menguji kelas parenting terhadap perubahan kognitif afektif dan psikomotor orangtua. 
Dinamika Sosial Budaya, Vol 20, No. 1, Juni 2018, pp 66-71

p-ISSN: 1410-9859\& e-ISSN: 2580-8524

http://journals.usm.ac.id/index.php/jdsb

\section{HASIL DAN PEMBAHASAN}

Hasil penelitian menunjukkan bahwa terdapat

perbedaan mean antara pretest dan posttest

sebagaimana tersaji dalam tabel 1.

Tabel 1 Mean Pretest dan Postest

\begin{tabular}{lcc}
\hline \multicolumn{1}{c}{ Cluster } & Pretest & Postest \\
Interaksi dan & & \\
komunikasi & & \\
orangtua dan & 8,73 & 9,64 \\
anak & & \\
Pembentukan & 4,89 & 4,89 \\
perilaku & & \\
Pemahaman & & \\
orangtua \\
mengenai \\
pendidikan anak
\end{tabular}

Pada klaster satu dan tiga terjadi kenaikan mean yang menunjukkan bahwa terdapat perubahan KAP terkait interaksi dan komunikasi pada anak serta pemahaman orangtua mengenai pendidikan anak usia dini. Sedangkan pada klaster dua menunjukkan angka rerata yang dihasilkan sama atau tidak terjadi perubahan KAP dalam klaster pembentukan perilaku.

Sejalan dengan hasil di atas, hasil wawancara dengan orangtua menunjukkan hasil bahwa orangtua orangtua memahami bagaimana berinteraksi dan berkomunikasi lebih efektif dengan anak serta mengenai pendidikan anak usia dini. Dalam pengamatan di lembaga, nampak orangtua mulai menunjukkan perubahan dalam aspek mengenali diri terkait dengan tuntutan pada anak, lebih peka pada kebutuhan diri dan anak, mengelola emosi mereka, serta berusaha menjalin interaksi yang menyenangkan. Sama halnya dengan pemahaman mereka terhadap proses pendidikan anak usia dini yang mengarah pada empat kecerdasan di masa depan serta menghadapi 
Dinamika Sosial Budaya, Vol 20, No. 1, Juni 2018, pp 66-71

p-ISSN: 1410-9859\& e-ISSN: 2580-8524

http://journals.usm.ac.id/index.php/jdsb

\section{DAFTAR PUSTAKA}

Gunarsa, S. (2004). Psikologi perkembangan anak dan remaja. Jakarta: Gunung Mulia.

Hurlock, E. (2011). Psikologi perkembangan. suatu pendekatan sepanjang rentang kehidupan. Jakarta: Erlangga.

Kementrian Pendidikan Nasional. (2011). Petunjuk teknis orientasi teknis peningkatan pemahaman program penguatan PAUD berbasis keluarga (Parenting). Jakarta: Kemendiknas.

Kementrian Pendidikan dan Kebudayaan. (2012). Model pelaksanaan program pendidikan keorangtuaan di lembaga pendidikan anak usia dini. Jakarta: Kemendikbud.

Sudjana, D. (2010). Pendidikan luar sekolah: Wawasan sejarah perkembanganfFilsafah dan teori pendukung asas. Bandung: Falah Production.

Sumarno, H. (2014). Pemahaman kompetensi parenting terhadap perkembangan sosial anak (Studi kasus pada kelompok anak bermain di Pakem, Sleman). Jurnal Pendidikan dan Pemberdayaan Masyarakat, 1(1). 